\title{
PANORAMA E PARTICULARIDADES DO PROGRAMA DE APRIMORAMENTO PROFISSIONAL EM SAÚDE
}

\author{
PANORAMA AND PROFESSIONAL ENHANCEMENT PROGRAM \\ CHARACTERISTICS OF HEALTH
}

Maria Virginia Righetti Fernandes Camilo ${ }^{1}$

\section{RESUMO}

Este artigo tem por objetivo trazer uma contribuição ao debate sobre a formação profissional e educação permanente, abordando um panorama sobre os Programas de Aprimoramento Profissional para a Saúde, modalidade de pós-graduação lato sensu instituída particularmente no Estado de São Paulo, respondendo a demanda por mudanças na atenção e prestação de serviços para a saúde incluindo outras profissões na atenção às necessidades da população. Analisa a origem do Programa e sua inserção no contexto das lutas pela redemocratização do país, mais especificamente do Movimento da Reforma Sanitária, a expansão desta modalidade de formação nos anos 90 e as particularidades que envolvem os Programas de formação do Serviço Social.

PALAVRAS CHAVE: Serviço Social. Formação Profissional. Política de Saúde. Ensino.

\begin{abstract}
This article aims to bring a contribution to the debate on vocational training and lifelong learning, covering an overview of the Professional Improvement Programs for Health, postgraduation courses mode particularly instituted in São Paulo, responding to demand for change the attention and services for health including other professions in the care of people's needs. Program analyzes the origin and their integration in the context of struggles for democratization of the country, specifically the Health Reform Movement Reformation, the expansion of this type of training in the 90s and characteristics involving the training Programs of Social Work.
\end{abstract}

KEYWORDS: Social Work. Vocational Training. Health policy. Education.

\footnotetext{
${ }^{1}$ Assistente Social, Doutora em Educação pela UNICAMP, Mestre em Serviço Social pela PUC São Paulo, Docente da Faculdade de Serviço Social da PUC Campinas, membro da direção da ABEPSS SUL II nas gestões 2011/2012 e 2013/2014.

Serv. Soc. \& Saúde, Campinas, SP v. 12, n 1 (15), p. 53-64 jan./jun. 2013 ISSN 1676-6806
} 


\section{INTRODUÇÃO}

As instituições representativas da categoria profissional dos assistentes sociais Conselho Federal de Serviço Social CFESS e Associação Brasileira de Ensino e Pesquisa em Serviço Social tem ampliado os debates sobre a inserção na área da saúde e suas particularidades principalmente a partir de dois elementos: o primeiro relaciona-se ao mercado profissional de trabalho que liderou por muitos anos a oferta, perdendo a liderança recentemente com a implantação da PNAS/ SUAS Sistema Único de Assistência Social em 2004/2005; o segundo elemento refere-se ao reconhecimento do Serviço Social como uma das 13 profissões da saúde pelo Conselho Nacional de Saúde, Resolução 208 de 8/10/1998.

Os debates ganham relevância com a autorização e regulamentação das Residências Multiprofissionais e em área profissional da saúde, criadas a partir da promulgação da Lei $n^{\circ} 11.129$ de 2005, orientadas pelos princípios e diretrizes do Sistema Único de Saúde (SUS), a partir das necessidades e realidades locais e regionais, abrangendo as profissões da área da saúde, a saber: Biomedicina, Ciências Biológicas, Educação Física, Enfermagem, Farmácia, Fisioterapia, Fonoaudiologia, Medicina Veterinária, Nutrição, Odontologia, Psicologia, Serviço Social e Terapia Ocupacional (Resolução CNS nº 287/1998).

Entretanto, sendo uma iniciativa pioneira do Estado de São Paulo, os Programas de Aprimoramento Profissional para a Saúde (PAP) não tem sido com frequência, acompanhada de debates no Serviço Social para somar esforços e avanços sobre o trabalho e formação em saúde. Este artigo traz uma contribuição no sentido de publicizar a questão com um panorama e particularidades desta formação para a saúde, abordando sua origem no contexto das lutas pela redemocratização e pela Reforma Sanitária, analisando suas especificidades e a demanda para esta formação pelos assistentes sociais.

Afinal a questão da formação e trabalho em questão se inscrevem no contexto de avanço de propostas e embates entre a saúde como política pública de direito regulamentada pela Constituição de 1988 e as propostas de privatização que apostam no mercado como prestador de serviço, combatendo as iniciativas do setor público com ataques, precarizando serviços com impacto negativo nas condições de trabalho, na formação em saúde e na qualidade dos serviços prestados.

Este artigo resulta em parte de estudo e pesquisa para tese de doutorado e em parte pelo exercício profissional na área da saúde como supervisora do Programa de Serv. Soc. \& Saúde, Campinas, SP v. 12, n 1 (15), p. 53-64 jan./jun. 2013 ISSN 1676-6806 
Aprimoramento Profissional desenvolvido pela Faculdade de Ciências Médicas da UNICAMP, mais especificamente junto ao Hospital de Clínicas, no período de 1999 a 2007. Trata-se, portanto de análise dos Programas de Aprimoramento Profissional para a Saúde, modalidade de formação lato sensu desenvolvida apenas no Estado de São Paulo, voltada à saúde pública, aos princípios e diretrizes do SUS, que insere os profissionais de Serviço Social e os embates que envolvem esta modalidade.

Nessa perspectiva está organizado a partir de breve apontamento sobre a origem do PAP origem associada à Reforma Sanitária, sua expansão nos anos 90 e as particularidades do Serviço Social nesta formação para saúde.

\section{A EMERGÊNCIA DOS PROGRAMAS DE APRIMORAMENTO PROFISSIONAL: A INFLUÊNCIA DA REFORMA SANITÁRIA.}

O percurso inicial de análise do Programa de Aprimoramento profissional se inscreve nas mudanças sinalizadas no mercado de trabalho do setor público, ampliado por profissionais vinculados à saúde, incorporando trabalhadores nos diferentes níveis de atenção da rede socioassistencial, quer nos serviços de maior complexidade como hospitais de referência terciária e quaternária, os serviços secundários e os serviços de maior cobertura populacional estruturado na atenção básica em saúde.

Ao mesmo tempo, a expansão do trabalho em saúde no setor público se relaciona ao contexto sociopolítico em que os Cursos de Aprimoramento emergem relacionados ao movimento que toma conta da sociedade brasileira nos anos 80 pela democratização e pelo fim da Ditadura. O Brasil experimenta neste período uma efervescência política em busca da democracia, da escolha dos representantes em todas as esferas através do voto, pela anistia política a líderes políticos, intelectuais e artistas, na luta pelos diretos de cidadania, nos quais se inclui a saúde.

A saúde e suas instituições tiveram um papel preponderante e histórico na ordem político e econômica brasileira, quer pela iniciativa da implantação dos serviços públicos de saúde, quer pelo modelo de Campanhas Sanitárias para controle de epidemias das áreas urbanas, ou mesmo mais tardiamente, pela política de assistência médica consolidada a partir da década de 30 , com a industrialização, a emergência da classe trabalhadora, com a formação dos Institutos de Aposentadorias e Pensões IAPs. 
Até este período a saúde era centrada na assistência médica, que tinha um caráter mais filantrópico, restringindo-se às associações de imigrantes e beneficentes. Luz (1986, p.70) afirma ser a primeira metade do século XX caracterizada pelo

[...] centralismo, vertical ismo e autoritarismo corporativo do lado da saúde pública; clientelismo, populismo e paternalismo, do lado das instituições deda Previdência Social, incluindo as de atenção médica.

A saúde foi historicamente um campo de embates e a III Conferência de Saúde ocorre em 1963, em plena efervescência política do governo Goulart propondo a municipalização da política entre as reformas sociais propostas.

Entretanto, o Golpe Militar de 1964 interrompe este processo e a centralização política e administrativa é retomada. O modelo assistencial resultante volta-se aos cuidados médicos individuais, com pouca ênfase nos problemas de natureza coletiva.

O Movimento da Reforma Sanitária emerge no período da Ditadura, fruto de um processo político em que a ausência de canais de representação política e a exclusão social provocam aproximações entre movimentos sociais com reivindicações para a saúde e o Movimento Sanitário, propondo outro modelo assistencial para a saúde, público e universalizado, tendo como premissa a defesa da "saúde como direito de todos e dever do Estado" (BRAVO, 1999). Discute a falência do modelo assistencial pautado prioritariamente em atos médicos, na atenção terapêutica, inserindo a saúde na esfera política ampliando o debate sobre a dimensão social do processo saúde/doença, relacionando às condições de vida e trabalho da população, concepção expressa o Relatório da VIII Conferência Nacional de Saúde de 1986:

No sentido mais abrangente, Saúde é a resultante das condições de alimentação, habitação, educação, renda, meio ambiente, trabalho, transporte, emprego, lazer, liberdade, acesso e posse da terra e acesso aos serviços de saúde. É assim antes de tudo, o resultado das formas de organização social da produção, as quais podem gerar grandes desigualdades nos níveis de vida.

Está no eixo central a defesa da universalização da política de saúde e a garantia de direitos, através do Sistema Único de Saúde SUS, redefinindo papeis institucionais do Município, Estado e União na prestação de serviços de saúde, financiamento do Estado, em consonância com os princípios de intersetorialidade, integralidade, descentralização, universalização e participação social.

Santos (2013) em um balanço crítico sobre o SUS analisa os obstáculos presentes no processo instituinte a partir de sua criação, colocando que o subfinanciamento federal era de $75 \%$ e caiu para 46\%; os estados e municípios que 
tinham 25\% elevaram o investimento para 54\% do financiamento público. Em 1999 com elevação da taxa de juros os municípios e estados são obrigados a limitar os gastos sociais, sendo que a Lei de Responsabilidade Fiscal estabelece limite para os gastos com pessoal, substituindo-os por terceiros como cooperativas, Organizações Sociais (OS) e Organizações não Governamentais (ONGs). A consequência é o crescimento de contratação de serviços privados complementares no SUS, conflitando com os princípios e diretrizes legais.

Esta perspectiva impacta negativamente na redução e do pessoal da saúde com "desumana precarização das relações de trabalho e da gestão do trabalho em saúde "Santos, (2013 p.275) estimando-se que 60\% dos trabalhadores são terceirizados. Ocorre uma contraposição entre as necessidades e direitos da população e a direção da política de saúde na atenção à população.

O cenário contemporâneo de avanço da perspectiva neoliberal, os ataques aos princípios e diretrizes do SUS vão se articulando pela presença de Organização de Sociedade Civil de Interesse Público OCIPs e das parceiras público privada, que sinalizam para a direção de ineficiência do Estado na oferta da saúde, como se a lógica do mercado, do lucro deva orientar as necessidades e desconstruir direitos legalmente instituídos.

Embora a presença dos Conselhos de Saúde em suas diferentes instâncias municipal estadual e federal tenham se constituído em avanço no tocante ao controle social, a representação não pode diminuir a força de mobilização dos movimentos sociais, espaço de politização da questão. A luta desencadeada pela Frente Nacional contra a Privatização s da Saúde resulta deste movimento em que a categoria dos profissionais de Serviço Social se inscrevem com representatividade.

Estes apontamentos conhecidos contribuem para situar a origem, o significado, a relevância do Programa de Aprimoramento Profissional para Saúde e os desafios postos como proposta de educação permanente.

A Saúde no Brasil passa por diversas por diversas transformações nos últimos 40 anos, principalmente pelo embate entre a saúde como direto de cidadania e dever do Estado, fruto do Movimento da Reforma Sanitária e a perspectiva neoliberal que propõe a redução do Estado nos investimentos, colocando o mercado como instância reguladora de políticas de atenção à saúde.

Serv. Soc. \& Saúde, Campinas, SP v. 12, n 1 (15), p. 53-64 jan./jun. 2013 ISSN 1676-6806 


\section{PAP: EVOLUÇÃO E EXPANSÃO NOS ANOS 90}

O Programa de Bolsas para Aprimoramento de médicos e outros profissionais de nível Superior que atuam na área da saúde foi criado pelo Decreto n ${ }^{\circ} 13.919$ de 11 de setembro de 1979, designado como Programa de Aprimoramento Profissional (PAP) foi criado no Estado de São Paulo como iniciativa para o aperfeiçoamento e a qualificação aos profissionais de saúde.

O PAP é um programa criado pelo Decreto Estadual nº 13.919, de 11/9/1979 destinado prioritariamente a recém graduados de diferentes cursos superiores, principalmente os da área da saúde, exceto Medicina, tendo em vista capacitá-los ao exercício profissional por meio do treinamento em serviço sob supervisão de profissional qualificado, em Instituições vinculadas ao Sistema Único de Saúde (SUS) e previamente credenciadas pela Fundação para o Desenvolvimento Administrativo (FUNDAP) da Secretaria de Gestão Pública e autorizadas pela Coordenadoria de Recursos Humanos da Secretaria de Saúde (CRH-SES) do Estado de São Paulo (MANUAL DO APRIMORAMENTO FUNDAP, 2013).

Sua evolução e expansão tem como marco a Constituição de 1988 e a criação do Sistema Único de Saúde SUS, colocando uma perspectiva legal para a ampliação dos serviços a saúde sob a responsabilidade do Estado, ocorrendo uma forte expansão nos anos 90 (CAMILO, 2005).

O PAP é definido como modalidade de ensino de pós-graduação lato sensu, voltado para a capacitação para a prática profissional das diversas categorias que integram os serviços de saúde. Os programas oferecidos para cada categoria profissional da saúde, tais como, Enfermagem, Nutrição, Psicologia, Serviço Social, Análises Clínicas, Odontologia, Terapia Ocupacional, Fonoaudiologia, entre outros, baseados no princípio de aprendizado em serviço, sob a supervisão direta de um profissional qualificado com titulação mínima de mestre ou três anos de experiência na área específica. Há programa multidisciplinares que não especificam a categoria profissional, aceitando egressos de nível superior que tenham afinidade com a área (FUNDAP,2010). As propostas dos Programas ofertados à categoria profissional específica ou multidisciplinar são elaboradas pelas instituições com 80\% de carga horária destinada às atividades práticas e $20 \%$ às teóricas. As propostas dos cursos são encaminhadas à FUNDAP e passam por avaliação de consultores externos, e se aprovadas, são autorizadas a funcionar. Os critérios para aprovação de um programa incluem a 
consonância com os objetivos do PAP, as condições de desenvolvimento e propostas com destaque pela relevância em relação às necessidades de saúde da população

Seus objetivos se inscrevem na capacitação e aperfeiçoamento profissional voltados ao trabalho no SUS com vistas à melhoria das condições de saúde da população. Os Programas de Aprimoramento são avaliados anualmente pelos alunos e as propostas são reavaliadas pela FUNDAP. A avaliação é contínua, possibilitando mudanças quanto aos objetivos e propostas.

O valor da Bolsa, atualmente é de R\$ 1.044,70 para carga horária de 40 horas semanais, perfazendo uma carga horária anual de, no mínimo, 1.760 horas, excluídas as horas correspondentes aos trinta dias de férias, sendo que, na constância do programa o estudante bolsista não poderá executar atividade profissional com vínculo empregatício.

O Programa de Aprimoramento Profissional estabelece como objetivos a proposta de complementação da formação universitária para a saúde pública, alinhada com os princípios e concepção de Saúde da Reforma Sanitária e do SUS.

Os objetivos do PAP se colocam na perspectiva de "complementar a formação universitária em aspectos da prática profissional não contemplados nos cursos de graduação; adequar a formação universitária à prestação de serviços de saúde voltados às necessidades da população; formar profissionais com uma visão crítica e abrangente do sistema de saúde, que possam a vir a atuar como agentes na implantação de um sistema universalizado, integrado, hierarquizado e regionalizado, voltado a melhorar as condições de saúde da população; formação de profissionais especializados numa área de atuação. (IZUMINO, PICCIAFUOCO; SHIRABAYASHI, 2000, p. 12-13).

A FUNDAP oferece vagas em mais de 300 programas, vários multidisciplinares com um ou dois anos de duração. Nas instituições ligadas diretamente às universidades que incluem estes Programas o aluno tem uma dupla titulação ao concluir o curso: de aprimorando e de Especialista reconhecido pelo MEC. Os certificados de conclusão de curso têm reconhecimento em concursos públicos do Estado de São Paulo, com pontuação conforme Resolução SS-7, de 12 de janeiro de 1996. Em sua justificativa, encontra-se de maneira clara, a relação entre três elementos: formação, emprego e necessidades de saúde da população; na intercessão dos três elementos encontra-se o lugar ocupado pelo PAP que deve:

Desenvolver-se em instituições públicas que sejam ao mesmo tempo formadoras (a instituições de ensino superior, que fornecem habilitações profissionais reconhecidas tais como faculdades e universidades) e 
empregadoras (o conjunto de serviços envolvidos com a prestação direta e indireta de serviços de saúde desde postos e serviços de saúde, hospitais gerais e especializados, serviços de diagnóstico, vigilância sanitária e epidemiológica, etc. hierarquizados segundo o nível de complexidade) e de recursos humanos (IZUMINO, PICCIAFUOCO, SHIRABAYASHI, 2000, p. 14).

Uma questão que se coloca refere-se à utilização de trabalho dos bolsistas como forma de diminuir os gastos para o setor de saúde. Observando a formação profissional na área verifica-se que esta é instituída tanto para os profissionais médicos na residência como para os não médicos, privilegiando a formação mediante a modalidade prática em serviço. A distribuição de responsabilidades se faz de forma hierarquizada com a supervisão de profissional qualificado como já apontado anteriormente. Esta relação relembra a qualificação de companheiros dos ofícios na constituição da sociedade salarial. Estes representavam, na época uma espécie de "aristocracia operária muito qualificada" (CASTEL, 1999, p. 187).

Os Programas de Aprimoramento passam por avaliações contínuas pelos alunos que o concluem e, segundo dados da FUNDAP (2013) em torno de $80 \%$ dos alunos fazem a avaliação, atribuindo notas de 8 a 10, sendo a atribuição da nota 10, a mais frequente. A questão da referência a identificação como mão de obra por parte dos alunos aparece em 16, 86\% das respostas, embora 78,98\% reconheçam e confirmam pelas respostas o "aprimoramento na área de formação". As questões abertas enfatizam a relação com a formação bem como, as críticas conforme depoimentos extraídos do documento (FUNDAP, 2013).

[...] grande aprendizado, porém, muitas vezes, éramos responsáveis por tocar o serviço”.

[....] se houvesse uma programação a ser seguida, consideraria como aprimoramento, mas, no caso, vejo como uma experiência”.

[...] foi mão de obra fora da área de formação; fazia trabalhos burocráticos, de secretariado, muitas vezes” (FUNDAP, 2013).

Em artigo Rossi e Bertani (2006) apontam aspectos que dificultam este tipo de formação. Apontam com destaque a questão da permanência no curso devido ao baixo valor da bolsa, a realização de tarefas simultâneas incluindo o uso do tempo no exercício da prática profissional, o empenho aos módulos teóricos, o desenvolvimento de monografia. A questão de formação em uma área da saúde, foco da especialização, e não uma proposta generalista apenas, restringe o conhecimento.

Quem são os egressos que buscam por esta modalidade de formação? Dados da FUNDAP (2013) apontam que a maior demanda procede de egressos de universidades 
públicas com 66\% (sendo 33\% de federais, 30\% de estaduais e 3\% de municipais) e 34\% são oriundos de instituições privadas de ensino.

O PAP tem início nos anos 80 com pequena oferta inicial de bolsas, em torno de 120, e a medida em que o Movimento da Reforma Sanitária se amplia e se consolida com o SUS, a oferta de bolsas amplia-se de maneira significativa, sendo os anos 90 um marco nessa mudança, chegando em torno de 1900 bolsas aprovadas, segundo dados da FUNDAP (CAMILO, 2005).

\section{O SERVIÇO SOCIAL NOS PROGRAMAS DE APRIMORAMENTO PROFISSIONAL}

Os primeiros Programas de Aprimoramento no campo da Saúde no Estado de São Paulo, especificamente na área de Serviço Social têm início no ano de 1984, a partir de duas propostas pioneiras nesta formação: "Serviço Social em Hospital de Cardiologia" desenvolvido no Hospital das Clínicas da Faculdade de Medicina da USP HCFMUSP e do Serviço Social em Psiquiatria da Faculdade de Medicina de Marília (FUNDAP, 2004). Nos anos seguintes são criadas mais propostas. Entretanto, a grande expansão ocorre na década de 90 com a implantação do SUS, em virtude da necessidade de formar profissionais, o que resultou na ampliação do número de bolsas já assinalada em tópico anterior.

Também os anos 90, marcam o Serviço Social como profissão avançando na direção das propostas de construção do Projeto Ético Político, materializando-se em dimensão político organizativa através do Conselho Federal de Serviço Social (CFESS), da Associação Brasileira de Ensino e Pesquisa em Serviço Social (ABEPSS) e da Executiva Nacional dos Estudantes de Serviço Social (ENESSO), na dimensão jurídico político profissional com o Código de Ética Profissional e a Lei que Regulamenta a Profissão Lei 8662/ 1993 e as Diretrizes Curriculares elaboradas pela ABEPSS em 1996 e aprovadas pelo MEC em 2001, para a formação profissional e na dimensão de produção do conhecimento que " tem como parâmetro a afinidade com a tendência teórico crítica do pensamento social" (REIS, 1998, p. 6).

Segundo dados da FUNDAP (2010), existem 35 Programas de Aprimoramento na área de Serviço Social, sendo uma demanda significativa, ocupando a $4^{\text {a }}$ posição Serv. Soc. \& Saúde, Campinas, SP v. 12, n 1 (15), p. 53-64 jan./jun. 2013 ISSN 1676-6806 
entre as demais profissões. A Psicologia lidera os Programas com 46 propostas. Portanto, os indicadores apontam que existe a demanda pela formação em saúde e o perfil dos que a buscam, são egressos, em sua maior parte, de instituições públicas de ensino.

Cumpre enfatizar e destacar um elemento significativo de iniciativa dos profissionais de Serviço Social da área da saúde: inseridos nos diversos espaços sócio ocupacionais da área da saúde, voltados ao SUS, elaboram propostas de formação que são aprovadas e destacadas como relevantes.

A formação em saúde do PAP traz como exigência o aprendizado em serviço, mas também privilegia o caráter investigativo da profissão que resulta em produção de um trabalho final em forma de monografia ou artigo, com apresentação pública dos resultados. Portanto, há uma produção sobre o Serviço Social nesta modalidade de pósgraduação a ser debatida, publicizada, que exige estudos e pesquisas.

A questão sobre trabalho e formação em saúde ganha destaque junto às organizações da categoria, sendo que em 2008 o CFESS constitui o Grupo de Trabalho “Serviço Social na Saúde”, incorporando discussões, sistematizações e deliberações do conjunto de assistentes sociais. Nessa perspectiva, o trabalho resulta em propostas estabelecidas e definidas nos Parâmetros para Atuação dos Assistentes Sociais na Saúde (2010), respondendo a uma demanda da categoria sobre orientações para respostas profissionais identificadas no cotidiano. Aponta os eixos para a atuação profissional no tocante o atendimento direto aos usuários, mobilização participação e controle social, investigação planejamento e gestão, assessoria, qualificação e formação. Observa-se que o Aprimoramento em Serviço Social se inscreve na direção dos eixos estruturantes do trabalho em saúde pela dimensão do atendimento direto aos usuários, pois estão vinculados ao aprendizado em serviços prestados diretamente à população no cotidiano, bem como, aos demais aspectos.

Uma questão a ser considerada se refere à formação teórica em que se destaca a centralidade nas propostas do SUS, com seus princípios e propostas da organização dos serviços, na perspectiva de política pública conforme preconiza a Constituição e a Lei Orgânica da Saúde. Entretanto, por vezes esta formação em Serviço Social pode fazer um mergulho na especificidade das demandas da saúde, particularizando as patologias, distanciando-se do eixo formativo das expressões da questão social (IAMAMOTO,1988) no processo saúde doença, distanciando-se das propostas hegemônicas do Projeto Ético Político da Profissão.

Serv. Soc. \& Saúde, Campinas, SP v. 12, n 1 (15), p. 53-64 jan./jun. 2013 ISSN 1676-6806 


\section{CONSIDERAÇÕES FINAIS}

Ao finalizar este trabalho, destaca-se a relevância do campo da saúde como espaço sócio ocupacional do assistente social em seus diferentes serviços de atenção, espaços esses que tem impacto no cotidiano da população, na perspectiva de defesa e ampliação do direito. A formação e a qualificação se colocam como uma demanda posta pela concepção de atenção às necessidades em saúde envolvendo condições de vida, trabalho que se relacionam ao processo saúde /doença como processo social.

A política de saúde, que define os caminhos do direito, vive o dilema de avanço legal e da realidade adversa na garantia de condições objetivas. Neste movimento contraditório, de disputas entre modelo assistencial centrado no sistema público de saúde - SUS - e no modelo impulsionado pela privatização, regulado pelo mercado, inserem-se os Cursos de Aprimoramento em Serviço Social, como forma de qualificação, envolvendo uma interconexão nas relações entre educação, saúde e trabalho. Educação, pois trata-se de formação na modalidade lato sensu, voltada ao trabalho e inserção sócio ocupacional nos serviços de saúde, em que ocorrem mudanças na oferta e relações de trabalho.

O percurso desta formação, com expansão nos anos 90, tem contribuições e aspectos a serem debatidos e aprofundados como as condições objetivas da formação pelo baixo valor da bolsa, pela contribuição na ampliação dos serviços resultando, por vezes, em formas de precarização de trabalho. Entretanto, a oferta de cursos em Serviço Social e a demanda pelos egressos sinalizam que esta opção de formação ocupa um lugar relevante para a profissão, por sua proposta de aprendizado em serviço e pelo caráter investigativo que impulsiona a produção do conhecimento. Este artigo, com uma visão panorâmica, é um convite inicial ao debate

\section{REFERÊNCIAS}

BRAVO, M. I. S. Serviço Social e Reforma Sanitária: lutas sociais e práticas profissionais. São Paulo: Cortez; Rio de Janeiro: Ed. UFRJ, 1996. BRASIL, Relatório FINAL da VIII CONEFRÊNCIA NACIONAL DE SAÚDE. 1986 
CAMILO, M.V. R. F. Programa de Aprimoramento Profissional para a saúde: qualificação de assistentes sociais. (Tese de Doutorado) Faculdade de Educação UNICAMP, Campinas, 2005

CASTEL, R. As Metamorfoses da Questão Social: uma crônica do salário. Petrópolis: Editora Vozes, 2 ${ }^{\text {a }}$ Edição. 1999

CONSELHO FEDERAL DE SERVIÇO SOCIAL CFESS. Parâmetros para atuação dos Assistentes Sociais na Saúde. 2010. Disponível in: http://www.cfess.org.br/arquivos/Parametros_para_a_Atuacao_de_Assistentes_Sociais na_Saude.pdf

FUNDAP. MANUAL DO APRIMORANDO. PROGRAMA DE APRIMORAMENTO DE PROFISSIONAL (PAP) disponível in: http://pap.fundap.sp.gov.br/arquivos/MANUAL\%20PAP\%202013f.pdf IAMAMOTO, M. V. O Serviço Social na contemporaneidade: trabalho e formação profissional. São Paulo, Cortez Editora, 1998.

LUZ, M. T. Notas sobre as políticas de saúde no Brasil e transição Democrática -anos 80. Phisis. Revista de Saúde Coletiva, nº 1, Rio de Janeiro, Relume Dumará, 1991.

SANTOS, N. R. SUS, Política Pública de Estado: seu desenvolvimento instituído e instituinte e a busca de saídas. Ciência \& Saúde Coletiva. Vol 118 n. 1 Rio de Janeiro, jan. $2013 . \quad$ Disponível em http://www.scielosp.org/scielo.php?script=sci_arttext\&pid=S1413-81232013000100028 REIS, M. B. M. Notas sobre o Projeto ético-político do Serviço Social. 1998. Disponível inhttp://www.funorte.com.br/files/servico-social/29.pdf

ROSSI, A. S.; BERTANI, I. F. Aprimoramento profissional: educação continuada na Lógica de mercado. Revista Ibero-Americana de Estudos .., 2007. piwik.seer.fclar.unesp.br

SANCHA, C. C.M; SHIRABAYASHI, M.; PICCIAFUOCO, P. R.F.; DIMITROV, P. Programa de Aprimoramento Profissional (PAP): a Formação Pós-graduada nas Profissões da Saúde e a experiência da FUNDAP em sua Implementação. In: SAMPAIO S. A. P. (Org.) Estudos e reflexões sobre a formação de especialistas na área da Saúde. São Paulo, Edições FUNDAP, 2010 disponível in http://pap.fundap.sp.gov.br/arquivos/PAP_-

Estudos_e\%20Reflexoes_sobre_a_Formacao_de_Especialistas_na_Area_da_Saude.pdf 